Article

\title{
Vehicle Dynamics Endured by Patients during Emergency Evacuation-Ambulance versus Helicopter
}

\author{
Thierry Serre $^{1}$, Claire Naude ${ }^{1, * \mathbb{D}}$ and Marc Fournier ${ }^{2}$ \\ 1 Laboratory of Accident Mechanisms, TS2, University Gustave Eiffel, 13300 Salon de Provence, France; \\ thierry.serre@univ-eiffel.fr \\ 2 Toulon Intercommunal Hospital, 83000 Toulon, France; MARC.FOURNIER@ch-toulon.fr \\ * Correspondence: claire.naude@univ-eiffel.fr
}

check for updates

Citation: Serre, T.; Naude, C.; Fournier, M. Vehicle Dynamics Endured by Patients during Emergency Evacuation-Ambulance versus Helicopter. Safety 2022, 8, 4 . https://doi.org/10.3390/ safety 8010004

Academic Editor: Tom Brijs

Received: 9 December 2021

Accepted: 18 January 2022

Published: 20 January 2022

Publisher's Note: MDPI stays neutral with regard to jurisdictional claims in published maps and institutional affiliations.

Copyright: (C) 2022 by the authors. Licensee MDPI, Basel, Switzerland. This article is an open access article distributed under the terms and conditions of the Creative Commons Attribution (CC BY) license (https:// creativecommons.org/licenses/by/ $4.0 /)$.

\begin{abstract}
In the event of a road accident, a quick intervention is crucial. The mobile emergency services take care of patients whose condition requires an emergency repatriation to a hospital, by land in an ambulance or by air in a helicopter. The main criteria for choosing the means of transport are the time required for repatriation and the patient's more or less critical state of health. Do the vehicle dynamic effects endured by the transported patient have an influence on their health condition? Vehicle dynamics data were recorded with a road data recorder for a period of 3 months, under real conditions of patient repatriation to a hospital; 39 trips were recorded by ambulance and 29 trips by helicopter. Significant differences in speed (average 42 versus $202 \mathrm{~km} / \mathrm{h}$ ) and distance travelled (average 23 versus $85 \mathrm{~km}$ ) were observed. The sustained effects are similar in helicopters and ambulances. The ambulance causes more abrupt variations in longitudinal and transversal directions, whereas the helicopter has more variations in vertical direction. The vibration level in helicopters is higher than in ambulances. These results can be considered as a first reference baseline for establishing a characterization of transported patients' exposure to vehicle dynamics.
\end{abstract}

Keywords: vehicle dynamics; emergency evacuation; helicopter; ambulance; safety

\section{Introduction}

In a road accident, response speed of the rescue services is essential. The quicker the victim is assessed, the quicker the injuries are treated, and the better are the chances of survival [1]. In general, during the management of a trauma patient, increased mortality is induced when the pre-hospital phase exceeds $1 \mathrm{~h} \mathrm{[2];} \mathrm{this} \mathrm{is} \mathrm{known} \mathrm{as} \mathrm{the} \mathrm{"golden} \mathrm{hour"} \mathrm{[3].}$ The first phase of the rescue is related to alert, which can be reduced by $40 \%$ in urban areas and $50 \%$ in rural areas with the new eCall systems [4]. The benefits of such a system are mainly based on a faster transmission of essential initial information about the accident, such as the type of accident and the precise location, which allows for a faster arrival of the rescue team at the scene. A Finnish prospective study estimated that such a system deployed in Finland could reduce road fatalities by $4-8 \%$ and deaths of motor vehicle occupants by $5-10 \%$ [5]. After the arrival of the emergency services and their assessment of the injuries and possible stabilization of the victim at the scene, the second phase of the intervention consists in transporting the patient or injured person to a hospital as quickly as possible. This phase is also decisive. It is of the utmost importance to choose a means of transport that is fast and adapted to the transportation of people in a deteriorated state of health.

In France, the Mobile Emergency and Resuscitation Service (SMUR) takes care of patients whose condition requires an emergency repatriation to a hospital, by land in an ambulance or by air in a helicopter. The main criteria for choosing the means of transport are the repatriation time, when it can be greatly reduced by helicopter compared to an ambulance, and the patient's more or less critical state of health. Helicopter transport 
is recommended for all pathologies where the time factor has a real impact on medical and therapeutic management [6]. According to some studies, the air transport of an adult patient with a major trauma significantly increases his chances of survival compared to land transport [7-10]. Other studies indicate that being transported by an air medical service does not have a positive impact on survival [11-14]. Some studies even show that air transport can be counterproductive for the patient's health status and that although there are indications for the use of helicopters, there are just as many medical contraindications and even more unjustified indications [15]. The methodological weakness of the available literature, and the considerable heterogeneity of effects and study methodologies, mean that no precise estimation of the benefit of helicopter transport is available [16,17].

The consequences of the type of transport have been studied from a global point of view and are the result of multiple factors related to the transport time and the condition of the patient, and the various treatments provided on the spot or during transport. However, do the vehicle dynamics on the transported patient have an influence on their health status? A study by Zhu et al. [18] showed that rats subjected to even small accelerations of the order of + or $-2 \mathrm{~m} / \mathrm{s}^{2}$ experienced an instantaneous increase in blood pressure of 1 point on average. This cardiovascular response caused by dynamic linear acceleration in conscious rats is similar to what can be observed in humans. Earlier work had shown that linear acceleration could cause rapid changes in heart rate and blood pressure in humans [19-21].

If the dynamic loads of the vehicle have an influence on the health status of the transported patient, it is important to acknowledge the differences in vehicle dynamics between an ambulance and a helicopter. The dynamic exposure with these emergency means of transport, both land and air, have been little studied to date. In the work of Bouchut et al. [22], the vibrations generated by an ambulance and a helicopter transport were compared for newborns transported by a French specialized emergency medical service. This study found that land ambulance transfers are characterized by a succession of numerous dynamic peaks, whereas helicopter transfers generate whole-body vibrations and a higher noise, usually with a gradual and predictable onset.

The aim of the study is to measure the levels of loads induced by the transport of injured or sick people in ambulances and helicopters, to evaluate their differences, and thus to provide objective elements to help to choose a preferred means of transport. For a land vehicle, the parameters of the vehicle dynamics are characteristic of the vehicle itself, the driving profile of the driver and the type of roads used $[23,24]$. For a helicopter, the dynamic behavior is related to complex physical mechanisms in terms of pitch attitude and stability, and is variable depending on the trajectory, the weather conditions and to a lesser extent on the pilot. Hence, it appears important to measure the dynamic behaviors of the vehicles in real-life conditions during the repatriation of patients or injured people to a hospital. The influence of vehicle dynamics effects on the human body depends on the intensity, speed of onset and direction of accelerations, which can be classified into three general categories: sustained (lasting more than $2 \mathrm{~s}$ ), transient (between $0.3 \mathrm{~s}$ and $2 \mathrm{~s}$ ) and vibratory (less than $0.3 \mathrm{~s}$ ). The main useful measurements are accelerations, which can be made in all three directions, longitudinal, transversal and vertical, but can be supplemented by measuring roll, pitch and yaw rates, particularly for transient loading.

\section{Materials and Methods}

\subsection{Experimentation}

Vehicle dynamics data were recorded in the area around Marseille at the APHM (Assistance Publique des Hôpitaux de Marseille) for a period of 3 months, under real conditions of patient repatriation to a hospital; 39 trips were recorded with a Citroën Jumper ambulance driven by several ambulance paramedics and 29 trips with an AC 135 T1 helicopter (Airbus helicopters, Marignane, France) and a single pilot.

The data collected during this experiment were recorded on a voluntary basis by the driver and the pilot, as the recording was deactivated by default. Only the actual driving or flying phases for a patient repatriation to the hospital were kept. Location and time-stamp 
data were not recorded for confidentiality reasons: only day/night information was known. For each trip, the severity of the patient's condition was unknown.

\subsection{Recording System}

For data collection, an "EMMA2" recorder (Onboard Recorders of Accident Mechanisms version 2, Figure 1) was used for both experiments. Designed and developed at the Accident Mechanisms Laboratory [25,26], this device served as an inertial unit, and recorded longitudinal (along the $X$ axis, Figure 2), transversal (along the $Y$ axis) and vertical (along the $\mathrm{Z}$ axis) accelerations, as well as the angular velocities of rotation around the same axes, namely respectively: roll speed, pitch speed and yaw speed. These data were acquired at a frequency of $100 \mathrm{~Hz}$. The vehicle speed was also recorded by the device at a frequency of $1 \mathrm{~Hz}$ via a GPS. The recording unit was fixed as close as possible to the vehicles' center of gravity on a flat, horizontal surface. A sensor reset procedure was carried out at the beginning of the experiment with the vehicle at rest.

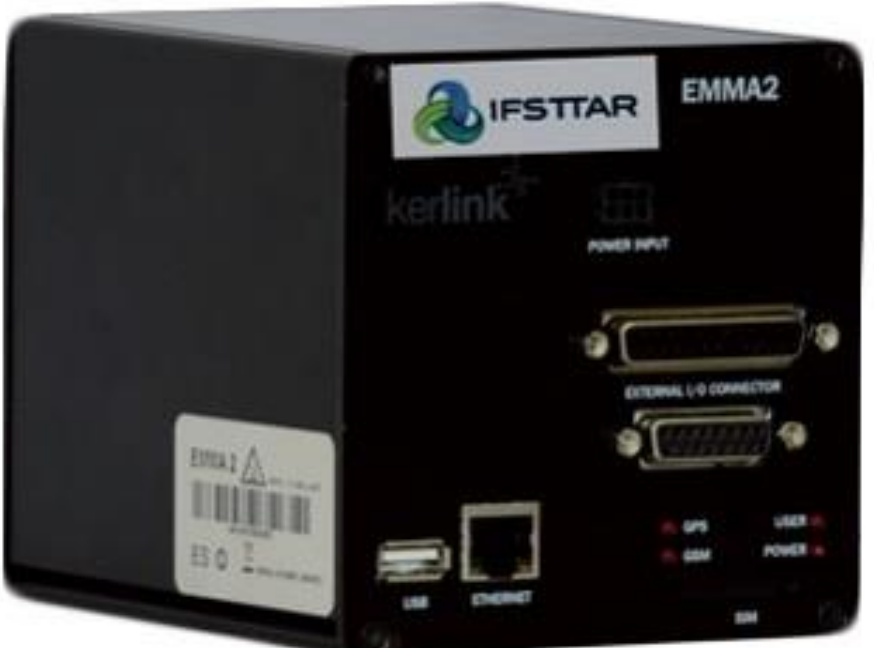

Figure 1. EMMA2 recording device.

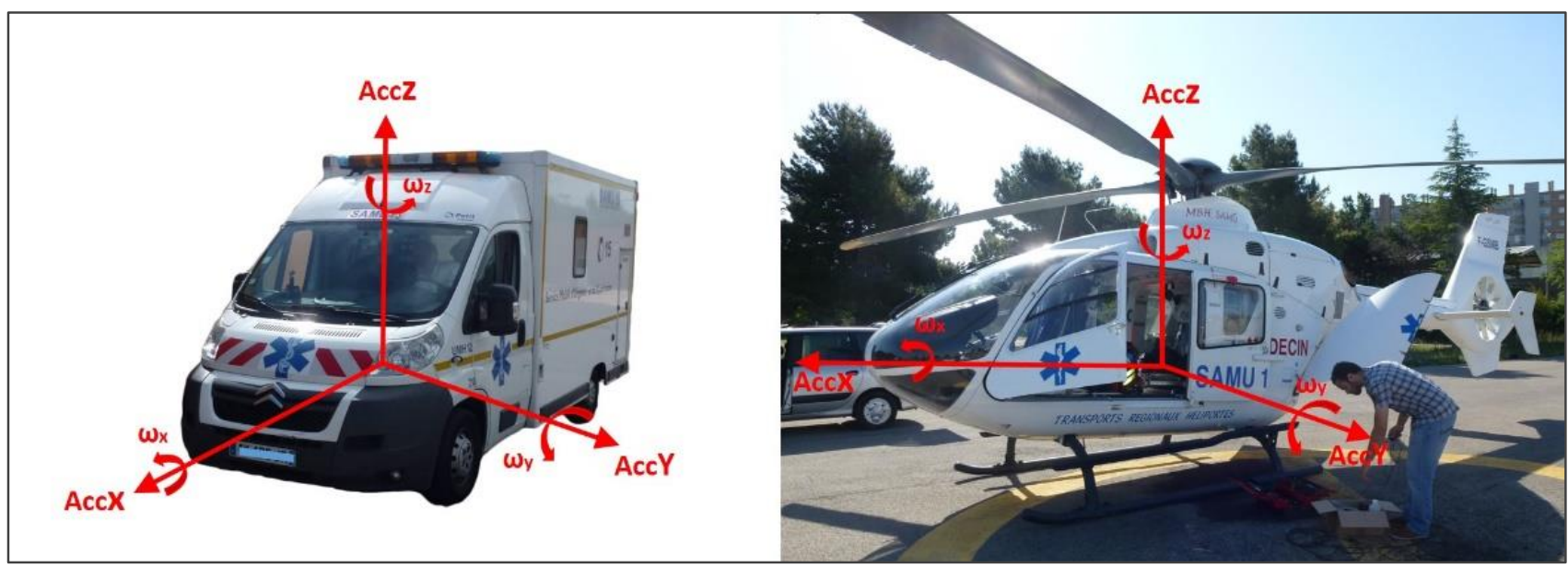

Figure 2. Coordinate system used for vehicles (ambulance and helicopter).

\subsection{Data Processing}

The vertical accelerations from the recording system are automatically corrected for gravity, and at rest are centered on 0 and not on $-9.81 \mathrm{~m} / \mathrm{s}^{2}$. The first pre-processing of the data consisted in correcting the acceleration offsets for some ambulance trips. Acceleration filtering was also necessary to attenuate the measurement noise and vibrations in order to 
study the real loads related to the vehicle movements. These vibrations are oscillations with a frequency of more than $30 \mathrm{~Hz}$ and are caused by the motorization of the vehicle itself, by the turbines, and the rotation of the helicopter blades. In the case of the ambulance, these vibrations are due to the contact between the tire and the road surface. A specific study allowed the comparison of these vibration levels and helped to determine the appropriate filtering for each vehicle. The calculations are based on the measured raw accelerations. Two indicators were calculated for all the trips of each vehicle:

- A simple indicator of the vibration level suitable for this type of acceleration recording is the average of the absolute value of the difference between the raw and filtered acceleration. This calculation allows keeping only the part of the signal that is unrelated to the dynamic behavior of the vehicle. Formula (1) corresponds to the longitudinal acceleration; it is to be used for the other accelerations, and for the acceleration norm.

- An indicator based on root mean square (RMS) accelerations of signals, which are often used to monitor the overall vibration level of a mechanical system and are interesting because they do not increase with isolated peaks in the signal [27]. They are calculated per time interval and measure the oscillatory content of the acceleration data [28]. The RMS of the raw accelerations were calculated over consecutive 1s periods (100 points at $100 \mathrm{~Hz}$ ) and then globally averaged over all trips for each vehicle. Formula (2) corresponds to the longitudinal acceleration and was applied to the other accelerations. An overall root mean square value is calculated according to Formula (3).

$$
\begin{gathered}
\mathrm{M}_{\mathrm{x}}=\frac{\sqrt{\left|\operatorname{Acc}_{\mathrm{X}}-\operatorname{Acc} \mathrm{f}\right|}}{\mathrm{RMS}_{\mathrm{x}}}=\sqrt{(1 / 100) \sum_{1}^{100} \mathrm{Acc}_{\mathrm{X}}{ }^{2}} \\
\text { normRMS }=\sqrt{\mathrm{RMS}_{\mathrm{x}}{ }^{2}+\mathrm{RMS}_{\mathrm{y}}{ }^{2}+\mathrm{RMS}_{\mathrm{z}}{ }^{2}}
\end{gathered}
$$

Apart from the global kinetic variables of the trips such as distance travelled, average speed and travel time, the characteristic quantities of the vehicle dynamics were compared: GPS speed, the three filtered accelerations (AccX, AccY, AccZ) and their norm (NormAcc), the three rotation rates $(\omega X, \omega Y, \omega Z)$ and their norm Norm $\omega$. The norms are calculated each time according to Formulas (4) and (5).

$$
\begin{gathered}
\text { NormAcc }=\sqrt{A c c_{X}^{2}+A c Y_{Y}^{2}+A c_{Z}{ }^{2}} \\
\text { Norm } \omega=\sqrt{\omega_{X}^{2}+\omega_{Y}^{2}+\omega_{Z}^{2}}
\end{gathered}
$$

As for the comparison of the sustained and transient dynamic loading levels experienced by the vehicles, spectra of each parameter were calculated, representing for all trips the time spent in each loading level, with intervals of $5 \mathrm{~km} / \mathrm{h}$ for speed, $1 \mathrm{~m} / \mathrm{s}^{2}$ for accelerations (filtered), and $10^{\circ} / \mathrm{s}$ for rotation rates. Acceleration peaks greater than $3 \mathrm{~m} / \mathrm{s}^{2}$ with a duration greater than $0.3 \mathrm{~s}$ were counted for all three directions.

\section{Results}

\subsection{Kinetic Characteristics of the Trips}

The 39 ambulance trips correspond to a total driving time of $14 \mathrm{~h}$ and a total distance of $900 \mathrm{~km}$. The 29 helicopter trips totaled $12 \mathrm{~h}$ of driving time and $2500 \mathrm{~km}$. The average duration of ambulance and helicopter trips was similar (21 $\mathrm{min} / 25 \mathrm{~min}$ ) but with a greater disparity for the ambulance: journey times between $4 \mathrm{~min}$ and $2 \mathrm{~h} 10 \mathrm{~min}$ for the ambulance and between $10 \mathrm{~min}$ and $1 \mathrm{~h}$ for the helicopter. The difference in standard deviation of the travel times reflects this difference (Table 1). The distances travelled by helicopter are on average 3 to 4 times higher than by ambulance, with an average speed 5 times higher, close to $200 \mathrm{~km} / \mathrm{h}$ in helicopters against $42 \mathrm{~km} / \mathrm{h}$ in ambulances. 
Table 1. Trips characteristics—ambulance (39), helicopter (29).

\begin{tabular}{cccccc}
\hline & Vehicle & Minimum & Maximum & Standard Deviation & Average \\
\hline Duration & Ambulance & $00: 03: 59$ & $02: 08: 16$ & $00: 27: 10$ & $00: 21: 13$ \\
[hh:mm:ss] & Helicopter & $00: 09: 41$ & $00: 59: 38$ & $00: 11: 28$ & $00: 24: 53$ \\
\hline Distance & Ambulance & 0.4 & 212.0 & 46.0 & 23.2 \\
{$[\mathrm{~km}]$} & Helicopter & 21.3 & 209.3 & 42.9 & 85.3 \\
\hline Speed & Ambulance & 0 & 162 & 28.4 & 42.4 \\
{$[\mathrm{~km} / \mathrm{h}]$} & Helicopter & 0 & 533 & 23.8 & 201.7 \\
\hline
\end{tabular}

\subsection{Vibrations and Acceleration Filtering}

For all 39 ambulance trips and 29 helicopter trips, the calculation of the vibrations with the three accelerations was undertaken using the difference between the raw signal and the 10-point rolling average filtered signal on the one hand and the root mean square of the signal on the other hand. The vibration levels are thus estimated by taking the global average of each of these two variables, and are illustrated in Figure 3 by considering the longitudinal acceleration for one trip of each vehicle. As for the ambulance, variations in the vibration level can be observed during a journey, depending on the roads taken and the speeds used, while for the helicopter the vibration level is quite constant in the stabilized phase and significantly higher than in the take-off and landing phases. The difference in vibration levels between the two vehicles can be clearly seen in the longitudinal acceleration of the two trips: there is significantly more vibration in the helicopter.
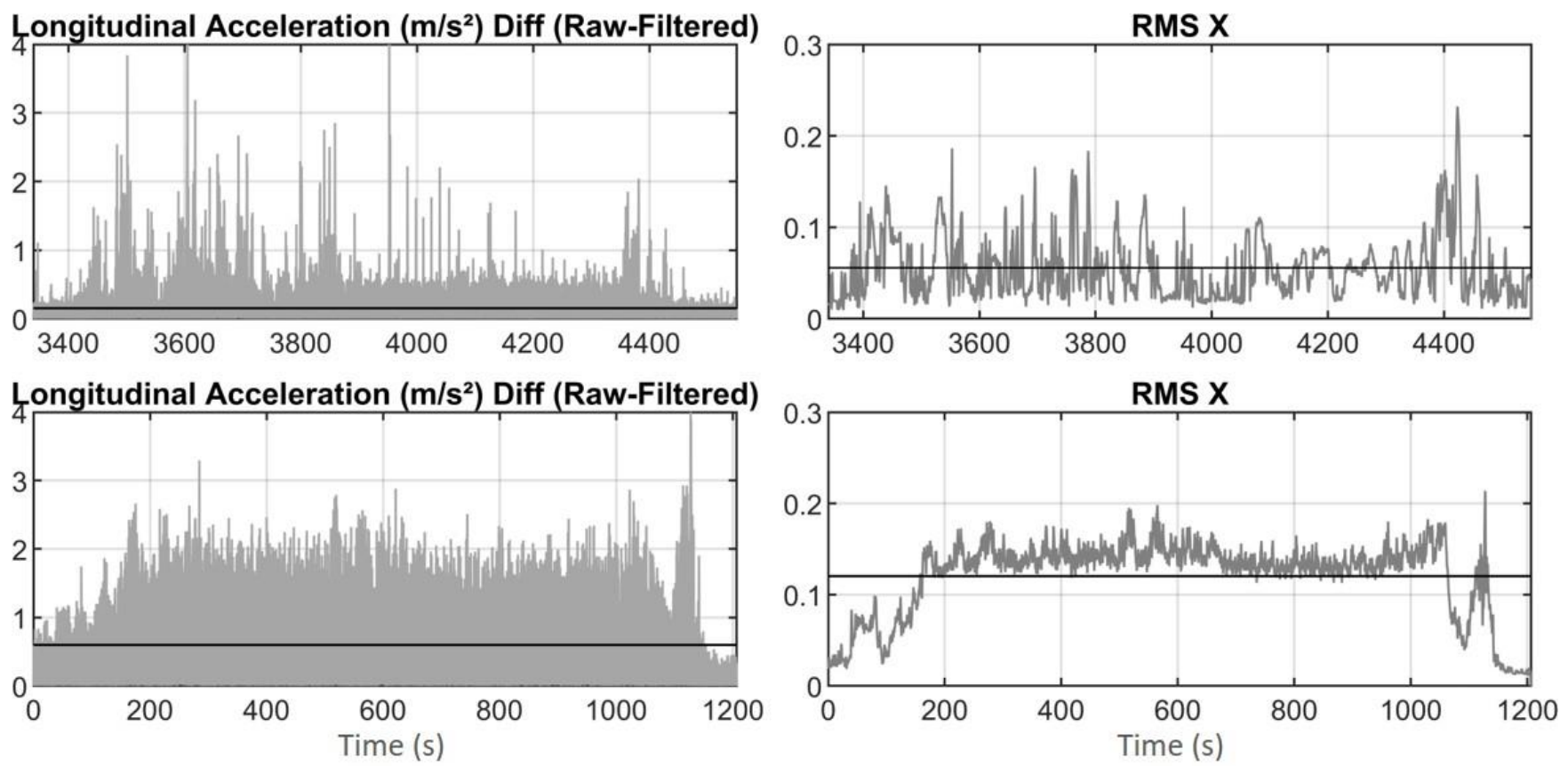

Figure 3. Examples of calculation of vibrations on longitudinal acceleration-ambulance trip (top), helicopter trip (bottom).

Table 2 of the results for the two types of calculations, for the three accelerations and the standards confirm that the vibration level is higher in the helicopter than in the ambulance. It is about three times higher using the first calculation in all directions, and between 1.7 and 2.7 times higher using the second calculation, except for transversal acceleration, where the vibration level is closer between the two vehicles. 
Table 2. Vibration levels in ambulance, helicopter, and ratio between the two vehicles.

\begin{tabular}{ccccccc}
\hline & \multicolumn{2}{c}{$\begin{array}{c}\text { Ambulance } \\
\text { (39 Trips) }\end{array}$} & \multicolumn{2}{c}{$\begin{array}{c}\text { Helicopter } \\
\text { (29 Trips) }\end{array}$} & \multicolumn{2}{c}{ Helicopter/Ambulance } \\
\hline Method & M & RMS & M & RMS & M & RMS \\
\hline X & 0.18 & 0.60 & 0.60 & 1.14 & 3.4 & 1.9 \\
Y & 0.17 & 0.57 & 0.39 & 0.56 & 2.4 & 1.0 \\
Z & 0.27 & 0.42 & 0.80 & 1.14 & 3.0 & 2.7 \\
Norm & 0.21 & 1.00 & 0.68 & 1.73 & 3.3 & 1.7 \\
\hline
\end{tabular}

For the study of the overall vehicle loads, a 10-point rolling average filter was applied to the ambulance accelerations and a 30-point rolling average filter to the helicopter accelerations, to account for the differences observed and evaluated earlier. The corresponding filters for the three accelerations are shown in Figure 4 for two $100 \mathrm{~s}$ periods of an ambulance trip and a helicopter trip.

Ambulance - Filter 10 pts

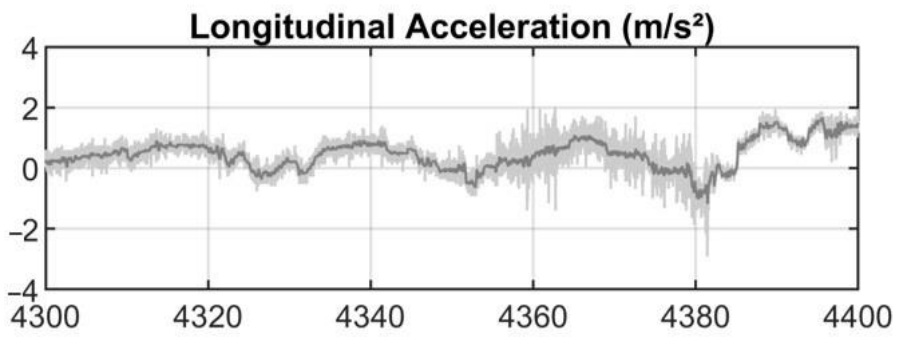

Lateral Acceleration $\left(\mathrm{m} / \mathrm{s}^{2}\right)$
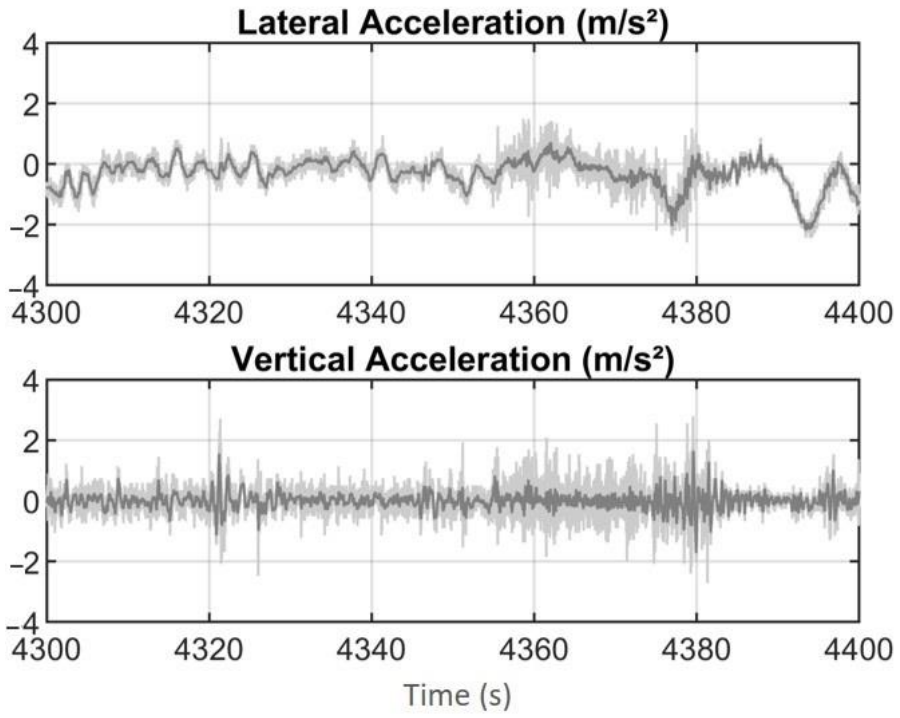

Helicopter - Filter 30 pts

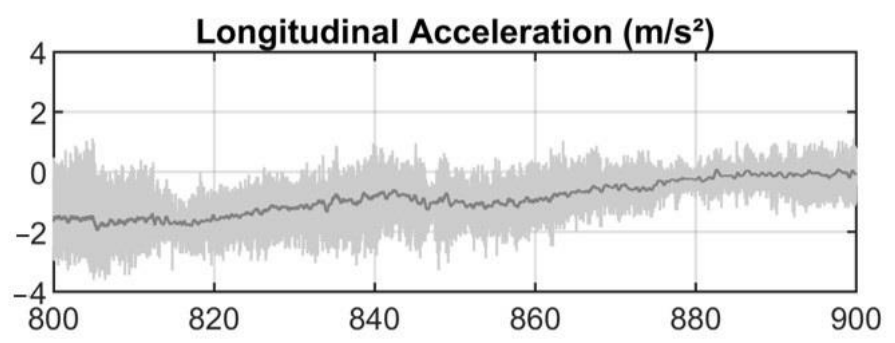

Lateral Acceleration $\left(\mathrm{m} / \mathrm{s}^{2}\right)$
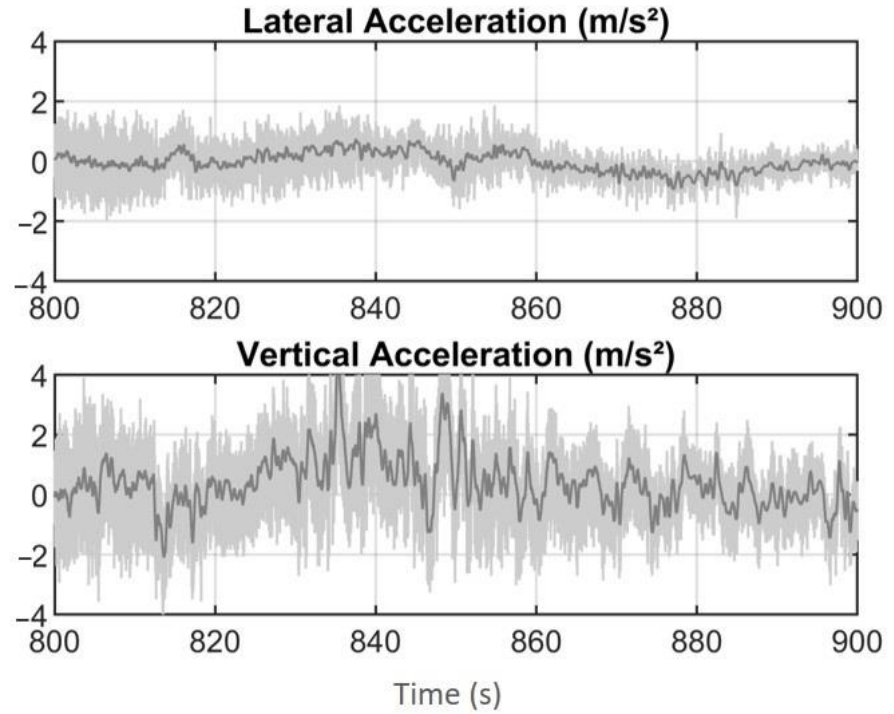

Figure 4. Acceleration filtering in ambulance and helicopter-examples over $100 \mathrm{~s}$ periods.

\subsection{Examples of Trips}

The signals of two trips of about $20 \mathrm{~min}$, one by ambulance, the other by helicopter, are shown in Figures 5 and 6 . The ambulance journey is quite typical, with probably some time on the highway, where the speed is around $120-130 \mathrm{~km} / \mathrm{h}$, preceded and followed by periods at lower speed, below $70 \mathrm{~km} / \mathrm{h}$, with frequent stops, potentially in urban or suburban areas. During these non-highway periods, longitudinal and transversal accelerations are highly variable, with braking, acceleration and directional changes distinctive of an urban trip. Yaw rate is also highly variable during these periods as it characterizes changes in direction and cornering. 

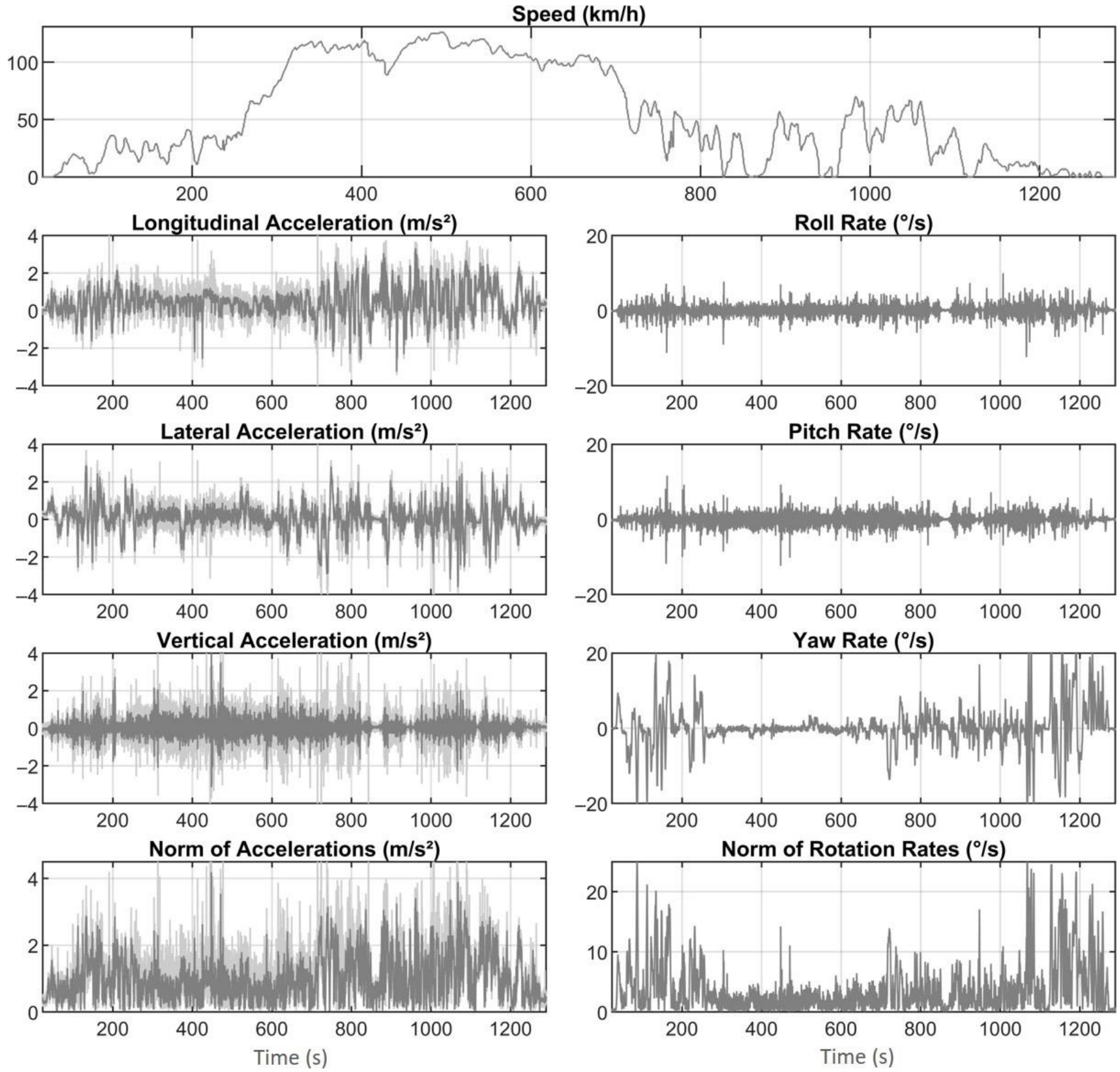

Figure 5. Vehicle dynamics parameters recorded during an ambulance trip—speed, filtered accelerations, rotational rates.

The helicopter trip is also typical, although among the fastest, with a take-off, an almost stabilized speed period around $260 \mathrm{~km} / \mathrm{h}$ and a final landing. The take-off and landing phases are particularly noticeable in the longitudinal acceleration, which after take-off remains stabilized at around $-1 \mathrm{~m} / \mathrm{s}^{2}$ due to the pitch attitude. The pitch attitude is the angle between the longitudinal axis of the helicopter and the horizontal plan. The helicopter attitude control is the action undertaken by the pilot to maintain a steady attitude. The other parameters are quite stable except during the take-off and landing phases. In the ambulance, there is more vibration in vertical acceleration than in the other types of accelerations, even after filtering. 

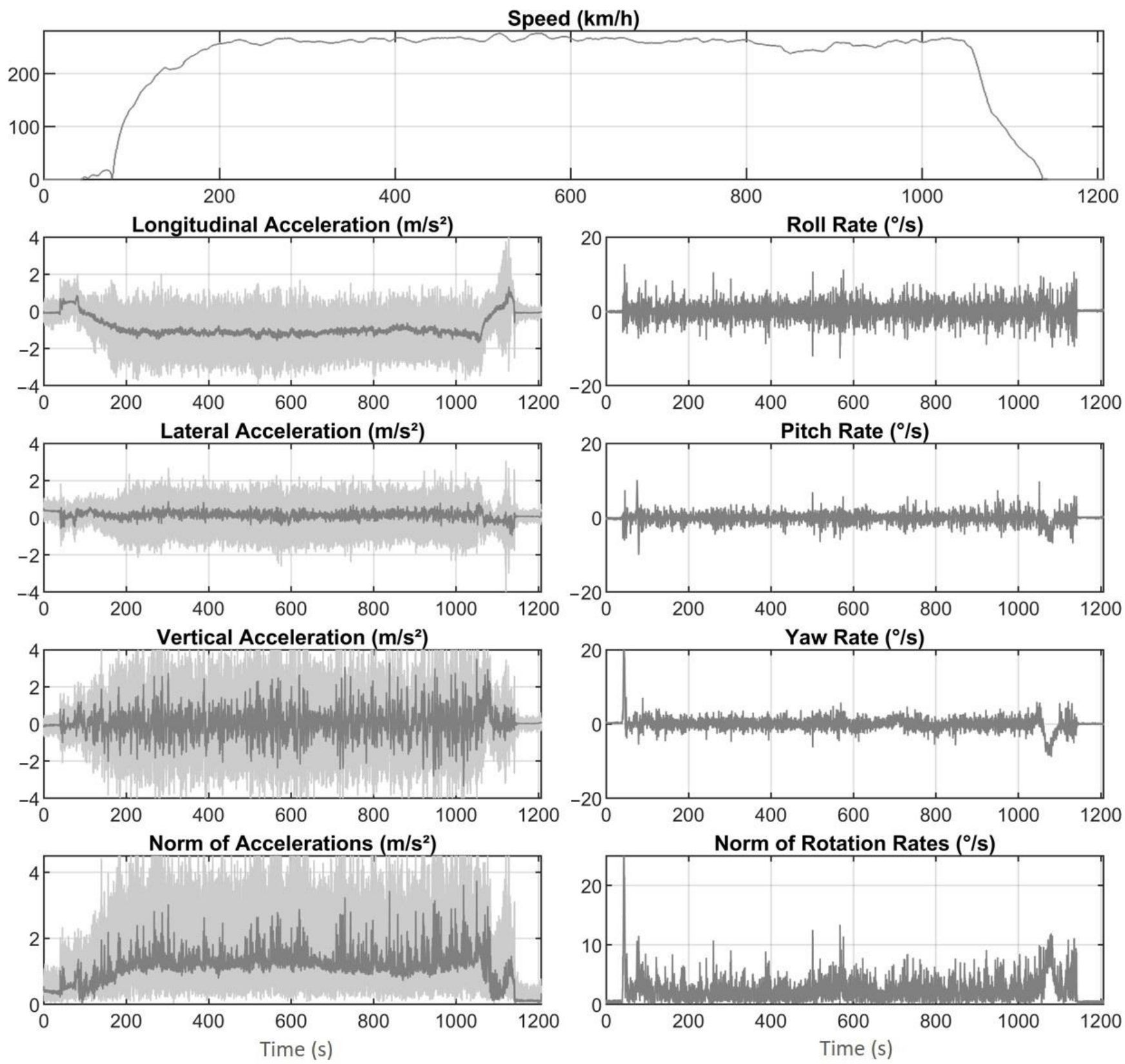

Figure 6. Vehicle dynamics parameters recorded during a helicopter trip—speed, filtered accelerations, rotational rates.

\subsection{Speed}

The speed distributions for all trips are compared in Figure 7. Most of the time spent in motion is spent at very different speeds. In ambulance, there are two main speed levels, around $30 \mathrm{~km} / \mathrm{h}$ and around $110 \mathrm{~km} / \mathrm{h}$, which correspond to trips in urban areas and on high-speed roads or highways. The most frequent cruising speeds in helicopters are situated in a $210-245 \mathrm{~km} / \mathrm{h}$ range. It should also be noted that $11.5 \%$ of the time is spent between 0 and $5 \mathrm{~km} / \mathrm{h}$ in an ambulance, compared to only $5 \%$ of the time in a helicopter. This time spent at low or no speed corresponds to frequent stops of the ambulance due to traffic, red lights and other stopping requirements, despite the possible use of the siren. The helicopter is not subject to the same constraints and its speed remains much more stable during a journey, apart from the take-off and landing phases. 


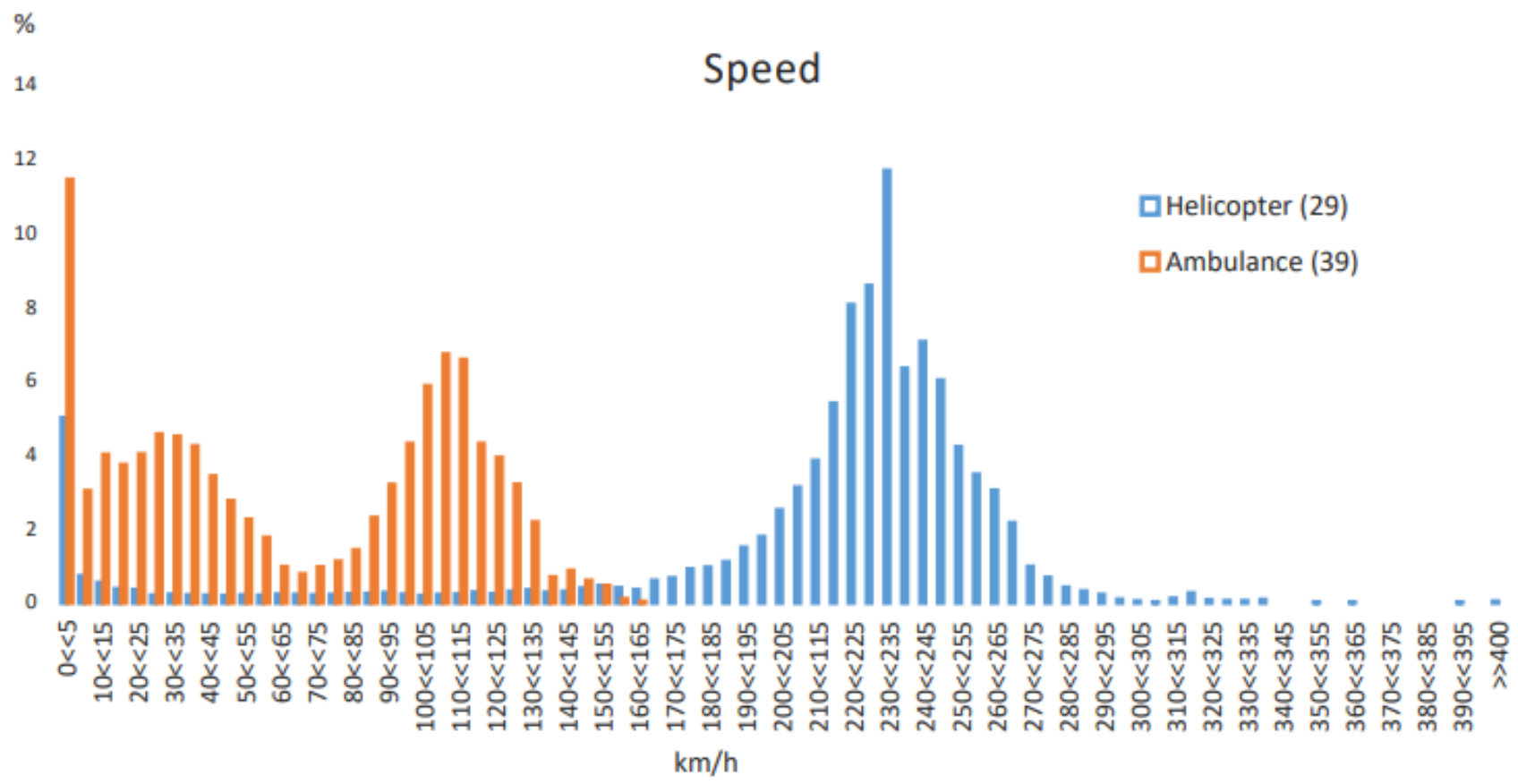

Figure 7. Speed distribution of ambulance and helicopter.

\subsection{Sustained Acceleration}

These differences in speed levels translate into different acceleration levels. In a land vehicle, longitudinal acceleration translates into positive values for vehicle acceleration and negative values for deceleration or braking. The transversal acceleration corresponds to the loads of cornering or changing direction at intersections, with positive values for left-hand turns and negative values for right-hand turns. The vertical acceleration reflects the vertical load caused by road layouts or defects, such as speed bumps or potholes, and is influenced by the longitudinal profile of the road. In a helicopter, due to the vehicle's pitch attitude, acceleration and braking are characterized by longitudinal acceleration, but also partly by vertical acceleration. In the case of turning, the acceleration is partly transversal and vertical, as the helicopter leans to the side. Therefore, it is interesting to compare the three accelerations of the two types of vehicle but also the norm of the accelerations in order to gain an overall idea of the differences in loading. Figure 8 shows the comparison of the time spent in each acceleration level.

These graphs highlight the different position of the two vehicles in space and, in particular, the forward leaning, or pitch attitude, of the helicopter which results in a shift in the longitudinal acceleration spectrum centered around $-1 \mathrm{~m} / \mathrm{s}^{2}$ for the helicopter, whereas that of the ambulance is centered around 0 . In terms of transversal acceleration, there is very little acceleration beyond $+/-1 \mathrm{~m} / \mathrm{s}^{2}(0.3 \%$ of the time $)$ in the helicopter whereas in the ambulance it is about $6 \%$ of the time beyond $1 \mathrm{~m} / \mathrm{s}^{2}$ (left turns) and $6.5 \%$ of the time beyond $-1 \mathrm{~m} / \mathrm{s}^{2}$ (right turns). In terms of vertical acceleration, by contrast, the ambulance is only slightly above $+/-1 \mathrm{~m} / \mathrm{s}^{2}, 1 \%$ of its time, while the helicopter spends $11 \%$ of its time above $+/-1 \mathrm{~m} / \mathrm{s}^{2}$. There are globally more vertical stresses in helicopters, but part of them can be a transfer of the longitudinal acceleration.

The figures for the accelerations norm distribution, which allows comparison of the overall load levels, are shown in Table 3. Both types of vehicle generate overall acceleration loads above $2 \mathrm{~m} / \mathrm{s}^{2}$ only $2.5 \%$ to $2.9 \%$ of the time. The only important difference between the two vehicles is below $2 \mathrm{~m} / \mathrm{s}^{2}$ : the helicopter generates more solicitations between 1 and $2 \mathrm{~m} / \mathrm{s}^{2}, 56 \%$ of the time, while in the ambulance this acceleration level is reached only $22 \%$ of the time. This difference in moderate and not in high acceleration is mainly due to the helicopter's pitch attitude, which generates a sustained acceleration around $-1 \mathrm{~m} / \mathrm{s}^{2}$. The higher level of vibration in the helicopter, especially on vertical acceleration, can also partly 
explain this difference, as the filtering is identical for the three accelerations of the same vehicle, and it did not necessarily remove all the noise in the three directions.

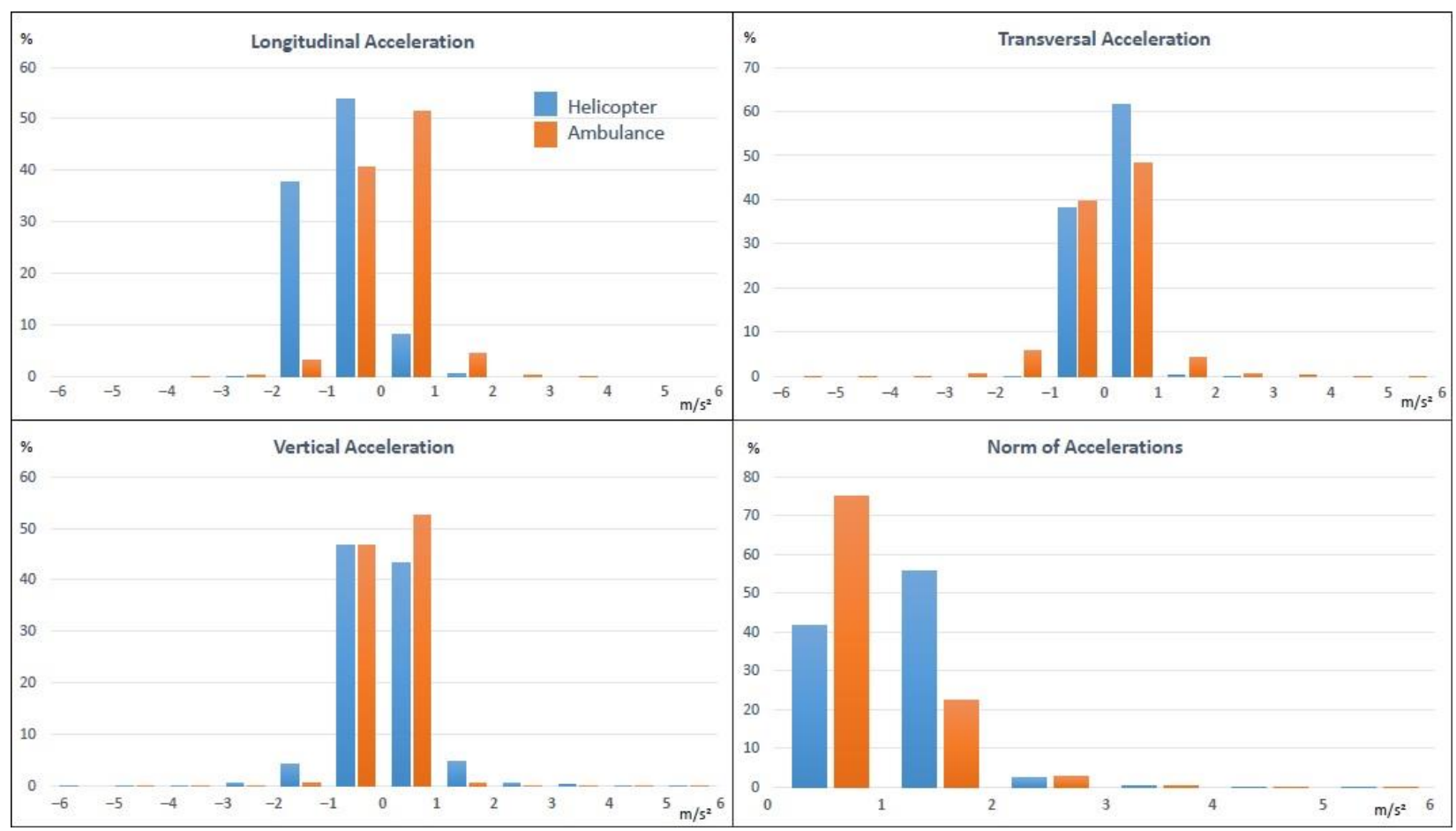

Figure 8. Comparison of acceleration levels in ambulance and helicopter.

Table 3. Comparative acceleration and rotation rate levels in terms of percentage of time spent.

\begin{tabular}{ccc}
\hline Norm of Accelerations & Ambulance (39) & Helicopter (29) \\
\hline$<1 \mathrm{~m} / \mathrm{s}^{2}$ & $74 \%$ & $42 \%$ \\
$1-2 \mathrm{~m} / \mathrm{s}^{2}$ & $22 \%$ & $56 \%$ \\
$2-3 \mathrm{~m} / \mathrm{s}^{2}$ & $2.6 \%$ & $2.3 \%$ \\
$3-4 \mathrm{~m} / \mathrm{s}^{2}$ & $0.25 \%$ & $0.20 \%$ \\
$>4 \mathrm{~m} / \mathrm{s}^{2}$ & $0.05 \%$ & $0.02 \%$ \\
\hline Norm of Rotation Rates & Ambulance (39) & Helicopter (29) \\
\hline$<10^{\circ} / \mathrm{s}$ & $95.4 \%$ & $99.2 \%$ \\
$10-20^{\circ} / \mathrm{s}$ & $4 \%$ & $0.7 \%$ \\
$20-30^{\circ} / \mathrm{s}$ & $0.7 \%$ & $0.1 \%$ \\
$>30^{\circ} / \mathrm{s}$ & $0.02 \%$ & $0.01 \%$ \\
\hline
\end{tabular}

The ambulance and helicopter are, therefore, rarely subjected to medium or high loads. In order to better evaluate and compare the transient phases with loads related to sudden changes in vehicle orientation, the levels of rotation rates were studied, as well as the acceleration peaks higher than $3 \mathrm{~m} / \mathrm{s}^{2}$ lasting more than $0.3 \mathrm{~s}$.

\subsection{Transient Loads}

\subsubsection{Rotation Rate}

The rotation rates are characteristic of the transient phases of pitching (acceleration or hard braking), rolling and yawing (turns). As shown in Figure 9, none of the vehicles experiences a roll speed above $10^{\circ} / \mathrm{s}$. However, in the ambulance a level of pitch and yaw rates between $+/-10$ and $+/-20^{\circ} / \mathrm{s}$ is reached $4.5 \%$ of the time, which is almost never the case in the helicopter ( $0.5 \%$ of the time). Table 3 shows that overall, the helicopter only 
reaches a rotation rate level above $10^{\circ} / \mathrm{s} 0.8 \%$ of the time, while the ambulance experiences rotation rates of this level about $4.7 \%$ of its travel time, i.e., almost six times more often.

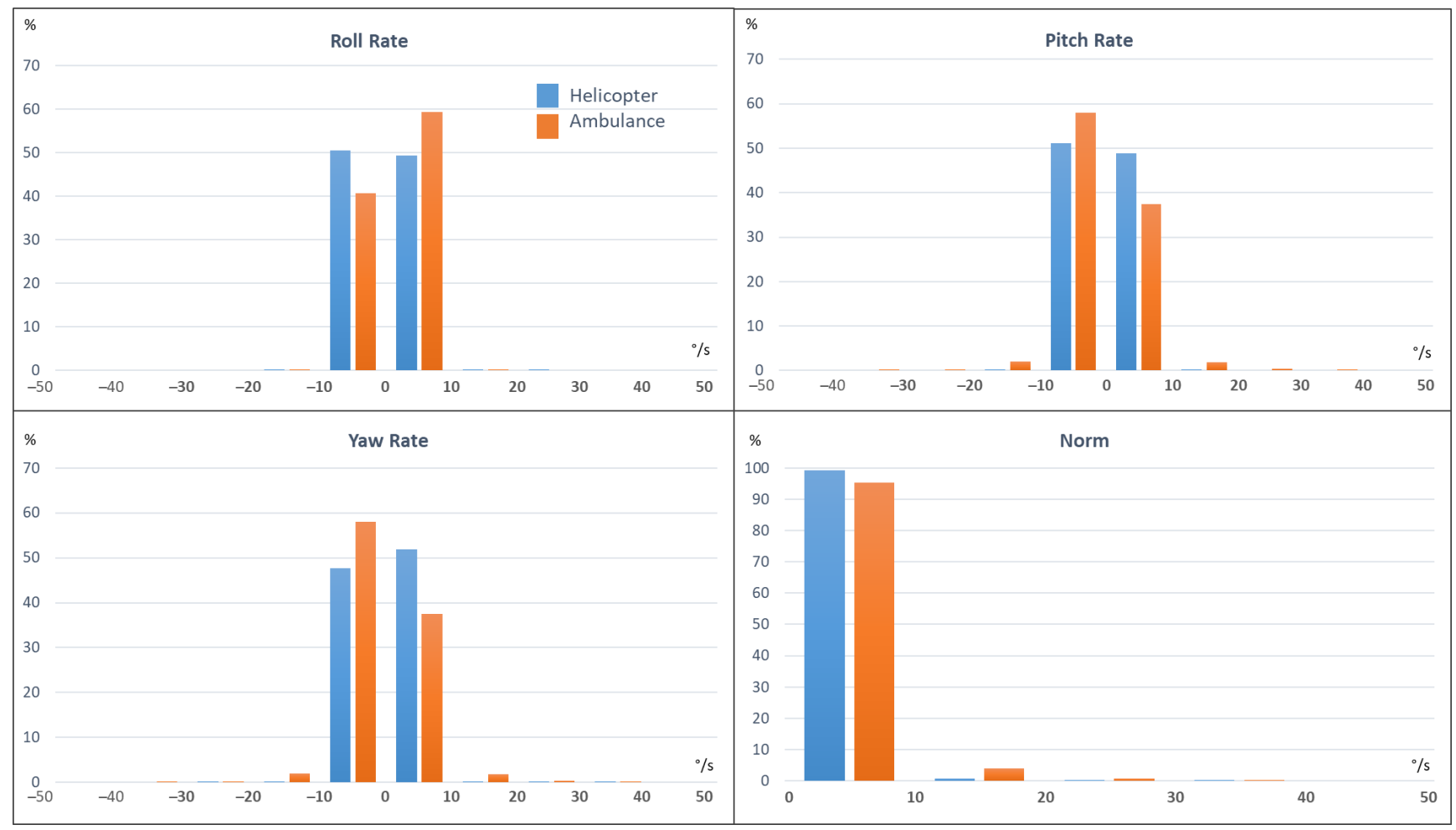

Figure 9. Comparison of rotation rate levels between ambulance and helicopter.

\subsubsection{Acceleration Peaks}

The maximum values of acceleration, braking, transversal and vertical acceleration peaks, positive or negative, were counted when they exceeded $3 \mathrm{~m} / \mathrm{s}^{2}$ over a duration of more than $0.3 \mathrm{~s}$, by counting together the peaks closer to $2 \mathrm{~s}$. This limit value of $3 \mathrm{~m} / \mathrm{s}^{2}$ was chosen because, overall, no situation of high acceleration, beyond $6 \mathrm{~m} / \mathrm{s}^{2}$ was observed even rarely, whereas it occurs in natural driving (see discussion). Figure 10 presents the results. Longitudinal and transverse acceleration peaks are detected in ambulances in 9 out of 39 trips, with only one braking situation, 8 strong acceleration situations and 33 strong transversal acceleration situations. In helicopters, peaks are observed only in vertical acceleration. There were 50 peaks identified on 14 out of 29 trips. In an ambulance, the maximum value reached is $5.5 \mathrm{~m} / \mathrm{s}^{2}$, with an average of $3.4 \mathrm{~m} / \mathrm{s}^{2}$ in longitudinal and $4.3 \mathrm{~m} / \mathrm{s}^{2}$ in transversal acceleration, and in a helicopter, the maximum value is $6.3 \mathrm{~m} / \mathrm{s}^{2}$, with an average value of $4.9 \mathrm{~m} / \mathrm{s}^{2}$ in positive vertical acceleration and $-4.4 \mathrm{~m} / \mathrm{s}^{2}$ in negative vertical acceleration. 


\begin{tabular}{|c|c|c|c|c|c|c|c|c|c|c|c|c|c|c|c|c|c|c|}
\hline & \multicolumn{2}{|c|}{$A \operatorname{cc} X>0$} & \multicolumn{2}{|c|}{$A c c X<0$} & \multicolumn{2}{|c|}{$A c c Y>0$} & \multicolumn{2}{|c|}{$A c c Y<0$} & \multicolumn{2}{|c|}{$A c c Z>0$} & \multicolumn{2}{|c|}{$A c c Z<0$} & \multicolumn{6}{|c|}{ Max values } \\
\hline Vehicle -Trip & $\mathrm{Nb}$ & $>2 \mathrm{~s}$ & $\mathrm{Nb}$ & $>2 \mathrm{~s}$ & $\mathrm{Nb}$ & $>2 \mathrm{~s}$ & $\mathrm{Nb}$ & $>2 \mathrm{~s}$ & $\mathrm{Nb}$ & $>2 \mathrm{~s}$ & $\mathrm{Nb}$ & $>2 \mathrm{~s}$ & $A c c X>0$ & $A c c X<0$ & $A c c Y>0$ & $A c c Y<0$ & $A c c Z>0$ & $A c c Z<0$ \\
\hline Ambulance - 1 & & & & & 2 & 2 & & & & & & & & & 3.5 & & & \\
\hline Ambulance - 2 & & & & & 2 & 1 & & & & & & & & & 3.4 & & & \\
\hline Ambulance - 3 & & & 5 & 4 & 4 & 4 & 8 & 7 & & & & & & -3.6 & 5.5 & -4.4 & & \\
\hline Ambulance - 4 & 1 & 1 & & & & . & 1 & 1 & & & & & 3.3 & 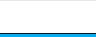 & & -3.6 & & \\
\hline Ambulance - 5 & & & 2 & 2 & 4 & 2 & 3 & 3 & & & & & & -3.6 & 5.4 & -5.2 & & \\
\hline Ambulance - 6 & & & & & 6 & 4 & 3 & 2 & & & & & & & 4.4 & -4.0 & & \\
\hline Ambulance - 7 & & & 3 & 2 & & & & & & & & & & -3.3 & & & & \\
\hline Ambulance - 8 & & & & & 5 & 4 & & & & & & & & & 3.6 & & & \\
\hline Ambulance - 9 & & & & & 3 & 3 & & & & & & & & & 4.6 & & & \\
\hline Helicopter - 1 & & & & & & & & & & & 1 & 1 & & & & & & -4.7 \\
\hline Helicopter - 2 & & & & & & & & & 1 & 1 & 1 & 1 & & & & & 4.3 & -4.1 \\
\hline Helicopter - 3 & & & & & & & & & & & 3 & 3 & & & & & & -4.3 \\
\hline Helicopter - 4 & & & & & & & & & 1 & 1 & 1 & 1 & & & & & 4.2 & -3.5 \\
\hline Helicopter - 5 & & & & & & & & & 1 & 1 & & & & & & & 4 & \\
\hline Helicopter - 6 & & & & & & & & & 2 & 2 & & & & & & & 5.4 & \\
\hline Helicopter - 7 & & & & & & & & & 2 & 1 & & & & & & & 6.3 & \\
\hline Helicopter - 8 & & & & & & & & & 2 & 2 & & & & & & & 5.1 & \\
\hline Helicopter - 9 & & & & & & & & & 2 & 2 & 2 & 2 & & & & & 3.7 & -4.1 \\
\hline Helicopter - 10 & & & & & & & & & 1 & 1 & & & & & & & 4.3 & \\
\hline Helicopter - 11 & & & & & & & & & 1 & 1 & & & & & & & 4.0 & \\
\hline Helicopter - 12 & & & & & & & & & 15 & 13 & 12 & 10 & & & & & 5.9 & -6.1 \\
\hline Helicopter - 13 & & & & & & & & & 3 & 3 & & & & & & & 5.4 & \\
\hline Helicopter - 14 & & & & & & & & & 4 & 3 & 1 & 1 & & & & & 6.0 & -4.1 \\
\hline Total & 1 & 1 & 10 & 8 & 26 & 20 & 15 & 13 & 35 & 31 & 21 & 19 & & & & & & \\
\hline Total by veh. & & & & & 2 & & & & & & & & & & & & & \\
\hline Total by veh. $>2 \mathrm{~s}$ & & & & & 2 & & & & & & & & & & & & & \\
\hline Mean & & & & & & & & & & & & & 3.3 & -3.5 & 4.3 & -4.3 & 4.9 & -4.4 \\
\hline
\end{tabular}

Figure 10. Number (total, spaced more than $2 \mathrm{~s}$ apart) and maximum values of acceleration peaks for the relevant trips.

\section{Discussion}

The ambulance/helicopter differential is less than might have been expected, particularly in terms of transient loads. However, it should be noted that overall, ambulance driving seems to be smoother than average car driving. According to two studies of natural driving [23,29], car drivers experience longitudinal accelerations (positive and negative) greater than $3 \mathrm{~m} / \mathrm{s}^{2}$ between 0.4 and $0.5 \%$ of their time, and lateral accelerations greater than $3 \mathrm{~m} / \mathrm{s}^{2}$ about $2 \%$ of the time. As for the ambulance, the corresponding percentages are $0.03 \%$ longitudinal and $0.2 \%$ lateral, i.e., more than 10 times less. It seems that paramedics drive more quietly, probably because they adapt their driving to the transport of sick or injured people in a deteriorated state of health. They have to make a compromise between the urgency of the transfer and the need not to shake the passenger too much.

As the levels of sustained and transient dynamic loads and vibration vary with the type of transport and with the flight or driving conditions, it would be interesting to assess the differences between the various models of ambulances and helicopters that make up the current fleet. This would make it possible to study which vehicle models are the least harmful and most comfortable for the patient. The dynamic loads are also highly dependent on the driver and, to a lesser extent, on the helicopter pilot. An experiment with a larger panel of drivers and pilots would be useful to estimate the driving dispersion induced by this type of transport and to make recommendations on the most favorable driving style for safe transport. The study could also be extended to other routes in other regions, with different types of road networks such as a mountainous road network, which is naturally different from urban and interurban networks in terms of vehicle dynamics. The comparison between ambulance and helicopter could thus be generalized, giving a more complete overview of the current technologies used daily by emergency services, and leading to avenues for improvement in the future.

This study confirmed that the vibration level resulting from helicopter transport is significantly higher than the vibration level of ambulance transport, but the relation- 
ship between vibration dose and health effects on the patient remains to be assessed. Existing studies on vibration exposure in a helicopter, such as those by Tamer [30] and Kasin et al. [31], consider that the pilots are exposed to hours of flying, thus much longer than transported patients, but they are still healthy unlike the latter. A more precise study of whole-body vibration exposure should be carried out according to the method defined in ISO 2631-1. Exposure times, maximum RMS values, and other specific variables calculated from accelerations in all three directions should be considered and the results compared to the standard values to determine the level of discomfort. The effects on a patient's degraded health status would still be very difficult to assess. In addition, the possible presence of a vacuum mattress, which reduces the effects of vibrations on the body, should also be considered.

\section{Conclusions}

Carried out in collaboration with the French mobile emergency services, this study highlights the differences between the dynamic exposure of a patient during transport by ambulance and during transport by helicopter.

First of all, it should be noted that the speeds used during interventions are obviously much higher in helicopters and the distances covered are greater on average. For journey times that are close on average, speed variations are much greater in ambulances.

In terms of global sustained loads, the only notable difference is observed at the level of moderate accelerations: the helicopter generates sustained accelerations between 1 and $2 \mathrm{~m} / \mathrm{s}^{2}$, i.e., $56 \%$ of the time, while in ambulance this level of acceleration is reached only $22 \%$ of the time. The main reason for this is the maintenance of a pitch attitude for the helicopter in stabilized flight, which generates a set longitudinal acceleration around $-1 \mathrm{~m} / \mathrm{s}^{2}$.

As for transient driving or piloting situations, a difference in rotation rates is observed. The ambulance reaches a rotation rate level higher than $10^{\circ} / \mathrm{s}$ almost six times more often, corresponding to $4.7 \%$ of the time, while the helicopter reaches this level only $0.8 \%$ of the time. The analysis of the acceleration peaks nuances this result. Only the ambulance induces high longitudinal and transversal accelerations occasionally, but vertical acceleration peaks of the same level or even higher are observed in helicopter, and these more frequently.

The vibration level is clearly higher in helicopters than in ambulances (between 1.7 and 3 times higher according to the calculation) except in transversal direction where the vibration level is closer between the two vehicles.

The loadings are, therefore, of the same overall level in helicopter and in ambulance, especially in terms of sustained acceleration. The ambulance causes more abrupt variations in longitudinal and transverse directions and the helicopter more in vertical directions, with a higher vibration level. This could have different consequences on the condition of the patients being transported depending on the type of injury or disease and their position in the vehicle. These results can be considered as a first reference basis to establish a characterization of the vehicle dynamics encountered by the transported patients.

In addition to the work presented in this article, a study is currently underway, based on a recent experiment with Puma and Caiman military helicopters used in conditions equivalent to the repatriation of war wounded. The results of this study will make it possible to compare the dynamic exposure of repatriated wounded in a military conflict situation with those recorded in helicopters under civilian repatriation conditions.

Once the levels of loads and vibration have been observed and evaluated, it remains to study their influence on the state of health of a patient or an injured person. A literature review by Araiza et al. [32] points out that certain contraindications may be negatively impacted by the higher altitude changes in air transport, especially hemorrhagic cerebrovascular accident (CVA), pneumocephalus, barotrauma, pneumothorax, pneumoperitoneum, and any type of recent surgery within a seven-day time frame. Carchietti et al. [33] also showed that vibrations may facilitate bleeding and worsen the prognosis of patients with pelvic fractures transported by helicopter emergency medical services. A study was re- 
cently carried out as a continuation of the present experiment with the aim of estimating whether the levels of loads commonly experienced by patients in ambulances have a negative influence on their state of health. The objective of this track experiment was to evaluate the influence of vehicle dynamics on patient physiological constants based on track tests with an ambulance and animals in a degraded state of health (by different levels of exsanguination). The tests were calibrated so that the stresses experienced by the ambulance were equivalent to those observed in real conditions and detailed in this study.

Author Contributions: Conceptualization, T.S. and M.F.; methodology, T.S. and C.N.; validation C.N. and T.S.; investigation, C.N.; writing-original draft preparation, C.N.; writing-review and editing, C.N. and T.S.; project administration, T.S. and M.F. All authors have read and agreed to the published version of the manuscript.

Funding: This research received no external funding.

Institutional Review Board Statement: The study was conducted in accordance with the Declaration of Helsinki, and the protocol was approved by the French Ethics Committee CERC-CTCV (14738, date of approval: 17 December 2018).

Informed Consent Statement: All subjects gave their informed consent for inclusion before they participated in the study.

Data Availability Statement: The recorded data used to support the findings of this study could be available from the corresponding author upon request.

Acknowledgments: The authors would like to thank those who participated in the experiment, namely: Romane CORNEN, Sébastien CHAUVET, Olivier BELLOT, Maxime DUBOIS-LOUNIS, Wilfried GAL, SMUR personnel (ambulance drivers, helicopter pilot). They also thank Marie-Sophie NAUDE for her proofreading of the English version of the article.

Conflicts of Interest: The authors declare no conflict of interest.

\section{References}

1. Sánchez-Mangas, R.; García-Ferrrer, A.; de Juan, A.; Arroyo, A.M. The probability of death in road traffic accidents. How important is a quick medical response? Accid. Anal. Prev. 2009, 42, 1048-1056. [CrossRef]

2. Bürki, L.; Yersin, B. «Golden hour» et manoeuvre de Sellick en urgence: Le bébé est-il à jeter avec l'eau du bain? Rev. Med. Suisse 2017, 13, 1373-1377. [PubMed]

3. Lerner, E.B.; Moscati, R.M. The Golden Hour: Scientific Fact or Medical “Urban Legend”? Acad. Emerg. Médecine 2001, 87, 758-760. [CrossRef] [PubMed]

4. European Union 2021. Available online: https:// ec.europa.eu/jrc/en/news/saving-lives-our-roads-ensuring-112-emergencyauto-call-technology-works (accessed on 8 December 2021).

5. Virtanen, N.; Schirokoff, A.; Luoma, J. Impacts of an automatic emergency call system on accident consequences. In Proceedings of the PSAPs Meeting on eCall, Madrid, Spain, 16 March 2006.

6. Braun, F.; Berthier, F.; Boudénia, K.; Carli, P.; Chollet-Xémard, C.; Cibien, J.-F.; De La Coussaye, J.-E.; Freysz, M.; Giroud, M.; Labourey, J.-M.; et al. Doctrine d'emploi des Hélicoptères dans le Cadre de L'aide Médicale d'Urgence; Conseil d'administration de Samu-Urgences de France: Aurillac, France, 2017. Available online: https:/ / www.samu-urgences-de-france.fr/medias/files/ doctrine-emploi-helico-sanitaires-amu-sudf-2017.pdf (accessed on 8 December 2021).

7. Ringburg, A.N.; Thomas, S.H.; Steyerberg, E.W.; van Lieshout, E.M.; Patka, P.; Schipper, I.B. Lives saved by helicopter emergency medical services: An overview of literature. Air Med. J. 2009, 28, 298-302. [CrossRef]

8. McVey, J.; Petrie, D.A.; Tallon, J.-M. Air versus Ground Transport of the Major Trauma Patient: A Natural Experiment. Prehosp. Emerg. Care 2010, 14, 45-50. [CrossRef] [PubMed]

9. Moront, M.L.; Gotschall, C.S.; Eichelberger, M.R. Helicopter transport of injured children: System effectiveness and triage criteria. J. Pediatr. Surg. 1996, 31, 1183-1188. [CrossRef]

10. Davis, D.P.; Peay, J.; Serrano, J.A.; Buono, C.; Vilke, G.M.; Sise, M.J.; Kennedy, F.; Eastman, A.B.; Velky, T.; Hoyt, D.B. The Impact of Aeromedical Response to Patients with Moderate to Severe Traumatic Brain Injury. Ann. Emerg. Med. 2005, 46, 115-122. [CrossRef] [PubMed]

11. Cocanour, C.S.; Fischer, R.P.; Ursic, C.M. Are scene flights for penetrating trauma justified? J. Trauma 1997, 43, 83-88. [CrossRef] [PubMed]

12. Schiller, W.R.; Knox, R.; Zinnecker, H.; Jeevanandam, M.; Sayre, M.; Burke, J.; Young, D.H. Effect of helicopter transport of trauma victims on survival in an urban trauma center. J. Trauma 1988, 28, 1127-1134. [CrossRef] [PubMed] 
13. Nicholl, J.P.; Brazier, J.E.; Snooks, H.A. Effects of London helicopter emergency medical service on survival after trauma. BMJ 1995, 311, 217-222. [CrossRef]

14. de Jongh, M.A.C.; van Stel, H.F.; Schrijvers, A.J.P.; Leenen, L.P.H.; Verhofstad, M. The effect of Helicopter Emergency Medical Services on trauma patient mortality in the Netherlands. Injury 2012, 43, 1362-1367. [CrossRef]

15. Goldstein, P.; Van Laer, V.; Mauriaucourt, P.; Lachery, P.; Marel, V.; Facon, A. Transports sanitaires héliportés. Pourquoi non? In Médecine D'urgence; Éditions scientifiques et médicales Elsevier SAS, et SFAR: Amsterdam, The Netherlands, 2000 ; pp. 69-76.

16. Butler, D.; Imran, A.; Willett, K. Is it the H or the EMS in HEMS that has an impact on trauma patient mortality? A systematic review of the evidence. Emerg. Med. J. 2010, 27, 692-701. [CrossRef] [PubMed]

17. Galvagno, S.M., Jr.; Sikorski, R.; Hirshon, J.M.; Floccare, D.; Stephens, C.; Beecher, D.; Thomas, S. Helicopter emergency medical services for adults with major trauma. Cochrane Database Syst. Rev. 2015, 12, CD009228. [CrossRef] [PubMed]

18. Zhu, H.; Jordan, J.R.; Hardy, S.P.; Fulcher, B.; Childress, C.; Varner, C.; Windham, B.; Jeffcoat, B.; Rockhold, R.W.; Zhou, W. Linear acceleration-evoked cardiovascular responses in awake rats. J. Appl. Physiol. 2007, 103, 646-654. [CrossRef]

19. Cui, J.; Iwase, S.; Mano, T.; Katayama, N.; Mori, S. Muscle sympathetic outflow during horizontal linear acceleration in humans. Am. J. Physiol. Regul. Integr. Comp. Physiol. 2001, 281, R625-R634. [CrossRef] [PubMed]

20. Monahan, K.; Ray, C. Limb neurovascular control during altered otolithic input in humans. J. Physiol. 2002, 538, 303-308. [CrossRef]

21. Yates, B.J.; Aoki, M.; Burchill, P.; Bronstein, A.M.; Gresty, M.A. Cardiovascular responses elicited by linear acceleration in humans. Exp. Brain Res. 1999, 125, 476-484. [CrossRef] [PubMed]

22. Bouchut, J.-C.; Van Lancker, E.; Chritin, V.; Gueugniaud, P.-Y. Physical Stressors during Neonatal Transport: Helicopter Compared with Ground Ambulance. Air Med. J. 2011, 30, 134-139. [CrossRef]

23. Lechner, D.; Perrin, C. The actual use of the dynamic performances of vehicles. Proc. J. Automob. Eng. 1993, 207, 249-256. [CrossRef]

24. Lechner, D.; Perrin, C. Methodology to study the dynamic behaviour of the driver-vehicle system. Tech. Pap. 1996, 19, 17-21.

25. Lechner, D.; Naude, C. Road incident analysis between naturalistic driving study and accident in-depth investigation. In Proceedings of the 1st International Symposium on Future Active Safety Technology TowardZero-traffic-accident, Tokyo, Japan, 5-9 September 2011.

26. Naude, C.; Serre, T.; Dubois-Lounis, M.; Fournier, J.-Y.; Lechner, D.; Guilbot, M.; Ledoux, V. Acquisition and analysis of road incidents based on vehicle dynamics. Accid. Anal. Prev. 2019, 130, 117-124. [CrossRef] [PubMed]

27. Igba, J.; Alemzadeh, K.; Durugbo, C.; Eiriksson, E.T. Analysing RMS and peak values of vibration signals for condition monitoring of wind turbine gearboxes. Renew. Energy 2016, 91, 90-106. [CrossRef]

28. Rogers, M.J.B.; Hrovat, K.; McPherson, K.; Moskowitz, M.E.; Reckart, T. Accelerometer Data Analysis and Presentation Techniques; 20546-0001. Report NASA TM-II3173; National Aeronautics and Space Administration: Washington, DC, USA, 1997.

29. Naude, C.; Serre, T.; Ledoux, V. Vehicle dynamics data collection to characterize the drivers' behavior. In Proceedings of the European Transport Conference, Barcelone, Spain, 4-6 October 2017. 14p.

30. Tamer, A.; Zanoni, A.; COCCO, A.; Masarati, P. Generalized Measure of Vibration Exposure for Helicopter Pilots. In Proceedings of the 45th European Rotorcraft Forum, Warsaw, Poland, 17-20 September 2019. Available online: https:/ / re.public.polimi.it/ retrieve/handle/11311/1111943/441401/TAMEA03-19.pdf (accessed on 8 December 2021).

31. Kasin, J.I.; Mansfield, N.; Wagstaff, A. Whole Body Vibration in Helicopters: Risk Assessment in Relation to Low Back Pain. Aviat. Space Environ. Med. 2011, 82, 790-796. [CrossRef]

32. Araiza, A.; Duran, M.; Surani, S. Aeromedical Transport of Critically Ill Patients: A Literature Review. Cureus 2021, 13, e14889. [CrossRef] [PubMed]

33. Carchietti, E.; Cecchi, A.; Valent, F.; Rammer, R. Flight Vibrations and Bleeding in Helicoptered Patients with Pelvic Fracture. Air Med. J. 2013, 32, 80-83. [CrossRef] 